Don Quichotte avant Don Quichotte? Les récits de chevalerie du XIV $\mathrm{Xu} \mathrm{XVI}^{\mathrm{e}}$ s. en France, Italie et Espagne: production et réception, éd. C. CROIZY-NAQUET, M. SZKILNIK

\title{
Elisabetta Barale
}

\section{(2) OpenEdition}

\section{Journals}

\section{Édition électronique}

URL : https://journals.openedition.org/studifrancesi/22312

DOI : $10.4000 /$ studifrancesi.22312

ISSN : 2427-5856

Éditeur

Rosenberg \& Sellier

\section{Édition imprimée}

Date de publication : 1 avril 2020

Pagination : 151-152

ISSN : 0039-2944

Référence électronique

Elisabetta Barale, "Don Quichotte avant Don Quichotte? Les récits de chevalerie du xiv au xv'es. en France, Italie et Espagne: production et réception, éd. C. CROIZY-NAQuET, M. szKILNIK », Studi Francesi [En ligne], 190 (LXIV | I) | 2020, mis en ligne le 01 avril 2020, consulté le 03 août 2021. URL : http:// journals.openedition.org/studifrancesi/22312 ; DOI : https://doi.org/10.4000/studifrancesi.22312

Ce document a été généré automatiquement le 3 août 2021.

\section{(†) $९$

Studi Francesi è distribuita con Licenza Creative Commons Attribuzione - Non commerciale - Non opere derivate 4.0 Internazionale. 


\title{
Don Quichotte avant Don Quichotte? Les récits de chevalerie du XIV ${ }^{\mathrm{e}}$ au $X \mathrm{XI}^{\mathrm{e}}$ s. en France, Italie et Espagne: production et réception, éd. C. CROIZY-NAQUET, M. SZKILNIK
}

\author{
Elisabetta Barale
}

\section{RÉFÉRENCE}

Don Quichotte avant Don Quichotte? Les récits de chevalerie du XIVXIve au XVIXVI e s. en France, Italie et Espagne: production et réception, éd. C. CROIZY-NAQUET, M. SZKILNIK, “Tirant” 22, 2019.

1 Nous rendons compte ici de trois contributions concernant les récits de chevalerie du $\mathrm{Xv}^{\mathrm{e}}$ siècle présentées lors d'un colloque (Paris, Université de Sorbonne Nouvelle, 30 mai- $1^{\text {er }}$ juin 2018) consacré à la réflexion critique qui a accompagné ces ouvrages dès la fin du XIII ${ }^{e}$ siècle; les articles consacrés au Moyen Âge sont signalés dans la section correspondante de la Rassegna.

Rosalind BROWN-GRANT (Fraternité et chevalerie dans la version bourguignonne de "Florence de Rome" - Chantilly, Bibliothèque du Château, ms. 652, pp. 119-144) se penche sur l'un des thèmes principaux de Florence de Rome, à savoir le contraste entre les frères Milon et Esmeré dans leur attitude vis-à-vis des devoirs chevaleresques et de la femme objet de leurs désirs. Après avoir comparé la mise en prose à sa source en vers, l'A. analyse le rapport texte-image; elle remarque notamment que les dessins du Maitre de Wavrin ornant le codex de Chantilly introduisent des éléments de nouveauté tant par rapport au roman qu'aux conventions iconographiques médiévales. En effet, bien que le texte ne fournisse aucune précision sur les changements physiques subis par les frères, 
l'artiste réserve une attention particulière à la caractérisation de leur «âge moral»: dans les premières illustrations, les deux chevaliers sont habillés de façon identique, car ils partagent les mêmes qualités, mais au fur et à mesure que la méchanceté de Milon s'affirme alors que la vaillance d'Esmeré persiste, ils sont respectivement représentés comme un jeune homme perpétuel et un roi âgé, dont l'aspect distingué suggère la supériorité de l'âme.

3 La critique portée par Cervantès sur l'incapacité de Don Quichotte de saisir l'écart entre le présent et le monde de la chevalerie suggère à Zrinka STAHULJAK (L'Empire des livres: imagination, matière d'Orient, et archive du possible aux Pays-Bas bourguignons, pp. 195-206) l'analyse du rapport entre les objectifs politiques des ducs de Bourgogne et la constitution d'une bibliothèque de plus en plus riche. En particulier, l'A. démontre que l'existence d'ouvrages touchant à la matière d'Orient (notamment, l'Histoire d'Alexandre de Vasque de Lucène, l'Histoire de Jason de Raoul Lefèvre, les Antiquités judaïques et la Guerre des Juifs de Flavius Josèphe) incarne les désirs de croisade des mécènes, tandis que l'Histoire d'Olivier de Castille et la mise en prose longue de Blancandin et l'Orgueilleuse d'amour par Jean de Créquy, dont l'espace géographique est centré sur la «Méditerranée du Nord», se révèlent emblématiques de la volonté de constituer la Bourgogne en empire. En synergie avec les projets princiers, la bibliothèque se donne donc à voir comme une carte des intérêts territoriaux de ses lecteurs et préfigure des avenirs potentiels.

Le Canarien, récit relatant la conquête des Îles Canaries en 1402 par deux aventuriers français - Jean IV de Béthencourt et Gadifer de La Salle - nous est conservé dans deux versions, l'une $[B]$ transmise par le manuscrit Rouen, BM, MM 129, l'autre $[G]$ par le codex London, BL, Egerton 2709. Jane H.M. TAYLOR («Desvoyé de la droitte voye...»: Gadifer de la Salle, Jean de Béthencourt et "Le Canarien", pp. 207-220) se focalise sur l'épisode-clé de l'histoire - le retour de Béthencourt de Castille après avoir été nommé seigneur des Canaries à l'insu de son compagnon de voyage - dans le but d'étudier les procédés sociolinguistiques dont les auteurs des copies se sont servis pour réaliser une œuvre de propagande en faveur de l'un ou de l'autre chevalier. De menus détails, tels que des répétitions et des annotations marginales insistant sur la notion de «compagnonnage» dans $G$ ou des interpolations et des litotes dans $B$, témoignent du fait que les enjeux rhétoriques de la laudatio ou de la condemnatio sont utilisés pour dénoncer la trahison de l'éthique chevaleresque de Béthencourt dans $G$ et le comportement inapproprié de Gadifer dans B. 